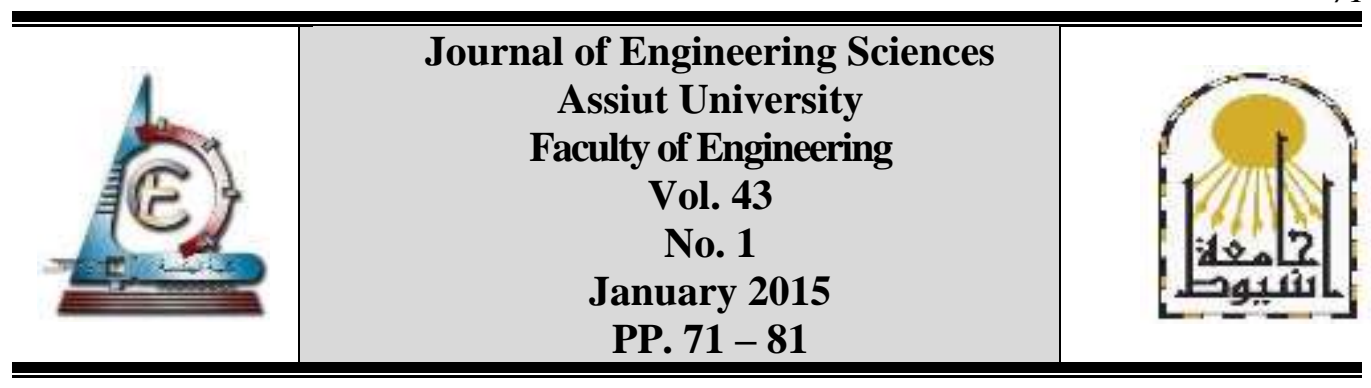

\title{
NUMERICAL MODELLING STABILITY ANALYSES OF HAULAGE DRIFT IN DEEP UNDERGROUND MINES
}

\author{
Wael Rashad Elrawy Abdellah \\ Mining \& Metallurgical Eng. Dept., Faculty of Engineering- Assiut University, Assiut, Egypt \\ Email address: waelabdellah@aun.edu.eg \& wre544@gmail.com
}

(Received 10 January 2015; Accepted 10 February 2015)

\begin{abstract}
Mine haulage drifts are the arteries of a mine. They are used for the transportation of blasted ore from the draw point to nearby ore pass or dumping point in deep underground mines. Thus, they must be remained functional during their service life. Otherwise, their instability could lead to serious consequences such as injuries, delay of production and increased operational cost. The objective of this paper is to evaluate the performance stability of mine haulage drifts with respect to mining step adopting numerical modeling of analysis. A two-dimensional, elastoplastic, finite difference code (FLAC 2D) is built for the purpose of this study. Haulage drift performance is evaluated using stability indicators and numerical modeling results are presented in terms displacement, stress and the extent of yield zones with espect to mining step.
\end{abstract}

Keywords:Tributary area method- Horizontal-to-vertical stress ratio- Room \& Pillar mining method- Coal mines.

\section{Introduction}

Haulage drifts are used for the transportation of blasted ore blocks from the draw point to nearby ore pass or dumping point in deep underground mines as shown in (Fig. 1). During production, haulage drifts are occupied by mine operators and mobile equipment. Therefore, their stability is important to the safe and uninterrupted production of a mining operation. It would be advantageous to know in advance the crucial factors influencing the stability of haulage drifts. Many factors may influence the stability of mine haulage drifts such as the strength and quality of the rock mass in which they driven and mining depth. As mines continue to reach deeper deposits, haulage drifts are expected to experience higher pre-mining stress conditions, thus suffering from more stability problems. The distance between haulage drifts and the orebody is another important factor affecting their stability. It is known that there exists a trade-off between drift stability (favoring long distance) and mining cycle (favoring short distance). Mining step is another important factor affecting the stability of mine haulage drifts. Different mining step will result in different mining-induced stresses, which in turn, will have varying influence on the mine haulage drifts stability condition. Other factors are the dip and thickness of orebody and the geometry of haulage drift. Haulage drift geometries are dictated by the size of mobile 
equipment. As reported in Canadian underground mines, these geometries vary between 4 $\mathrm{m}$ and $5 \mathrm{~m}[1-2]$.

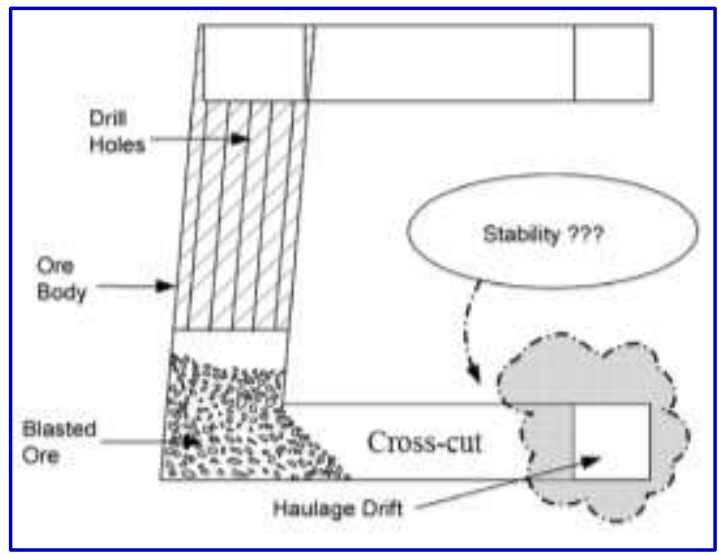

Fig. 1. Vertical section shows haulage drift as only stope access in deep mines

\section{Methods of stability analysis}

Stability analysis is one of the most important tools in underground mining control. As is already recognized by rock mechanics practitioners, analytical methods such as those provided by [3-6] cannot provide adequate solutions for complex mining problems. Therefore, empirical methods; such as the stability graph method for stope design, have become widely used in underground mines. These methods are based on past experiences and rock mass classification systems. They employ certain geotechnical characteristics of the rock mass to provide guidelines on stability performance and to determine the rock support requirements.

At this time, empirical methods do not take into account some of the factors which are known to influence the stability of the haulage drift such as the effect of nearby mining activity. In recent years, numerical methods have become widely accepted in mine design and feasibility studies. Numerical methods have the potential not only to solve complex mining problems, but also to help engineers and researchers better understand and assess failure mechanisms, estimate geotechnical risks, and design rock reinforcement systems more effectively. Figure 2 shows the different methods that could be adopted to assess the stability of mine haulage drifts.

To evaluate the performance stability of mine haulage drift (e.g., as depicted in Figure 2 above), three possible ways exist: deterministic analysis, sensitivity analysis, and stochastic approach. In deterministic analysis, average values of the parameters are used as inputs for the simulation model. However, the single values do not give any information about the variability of the input parameters. In a sensitivity analysis, a single parameter is systematically varied (e.g., based on the coefficient of variation) while all the other parameters are kept constant. The sensitivity analysis provides an understanding of the effect of each parameter on the overall behavior of the model; however, it produces an output with limited practical use. The stochastic analysis is known as a probabilistic method. This method is used to quantify the inherent uncertainty associated with rock mass input parameters. In this study, the first method; deterministic analysis; is only introduced and discussed here. 


\subsection{Deterministic analyses and model set up}

Numerical modelling is performed using Itasca's FLAC2D software [7]. The mean values for all rock mass parameters are used in the deterministic analysis (Table 1). To examine the stability of mine haulage drift, a typical sectional model is built using FLAC2D software as shown in Figure 3. The studied zone is divided into three areas; hanging wall, ore body and footwall. The ore body consists of massive sulphide rock (MASU). The hanging wall contains Metasediments (MTSD) and the footwall comprises of Greenstone rock (GS). The haulage drift is driven in the footwall parallel to the ore body for the length of its strike (approximately $200 \mathrm{~m}$ long) with cross section dimensions of $5 \mathrm{~m}$ by $5 \mathrm{~m}$ with a slightly arched roof. The thickness of the ore body is $30 \mathrm{~m}$ and the haulage drift is situated at $1500 \mathrm{~m}$ below ground surface and at $25 \mathrm{~m}$ apart from the nearest ore body (e.g., stope 3 ). The rock mass properties and backfill mechanical properties are listed in Table 1.

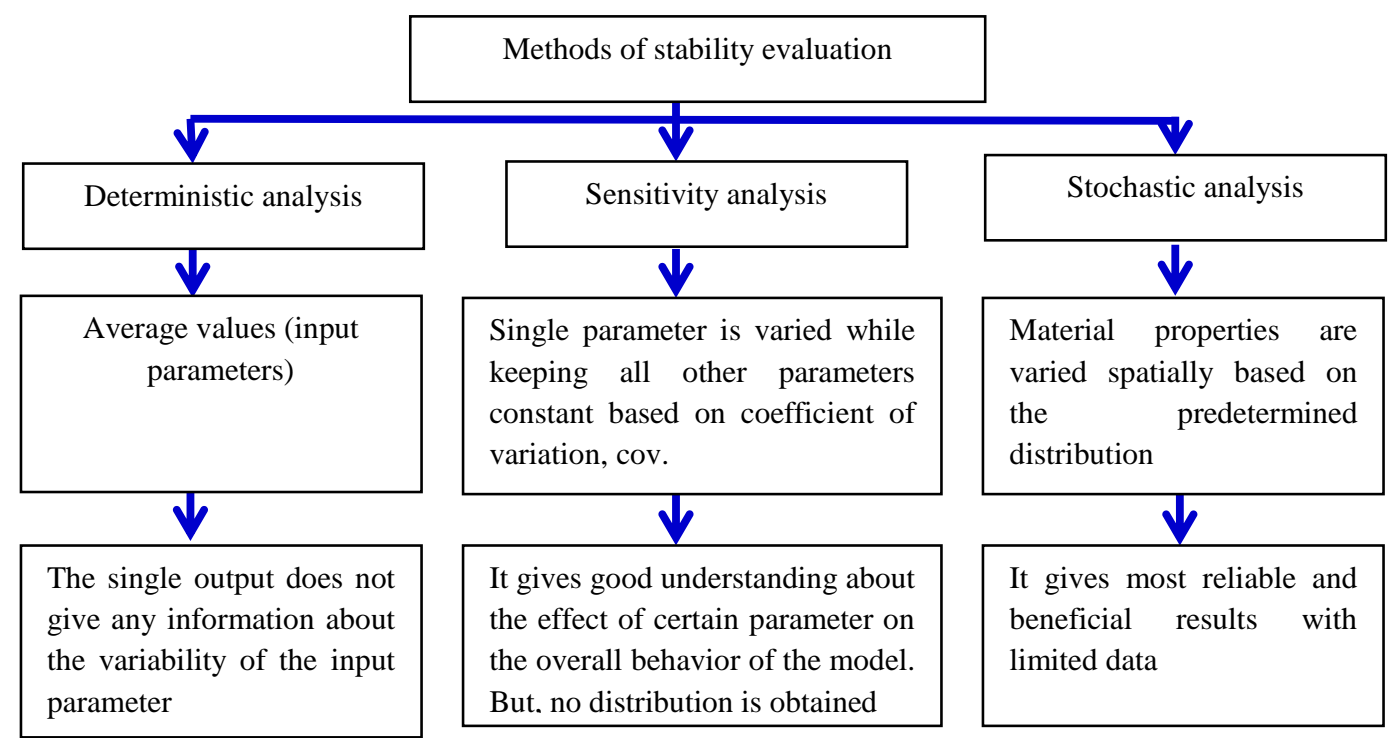

Fig. 2. Methods of haulage drift stability analysis [1]

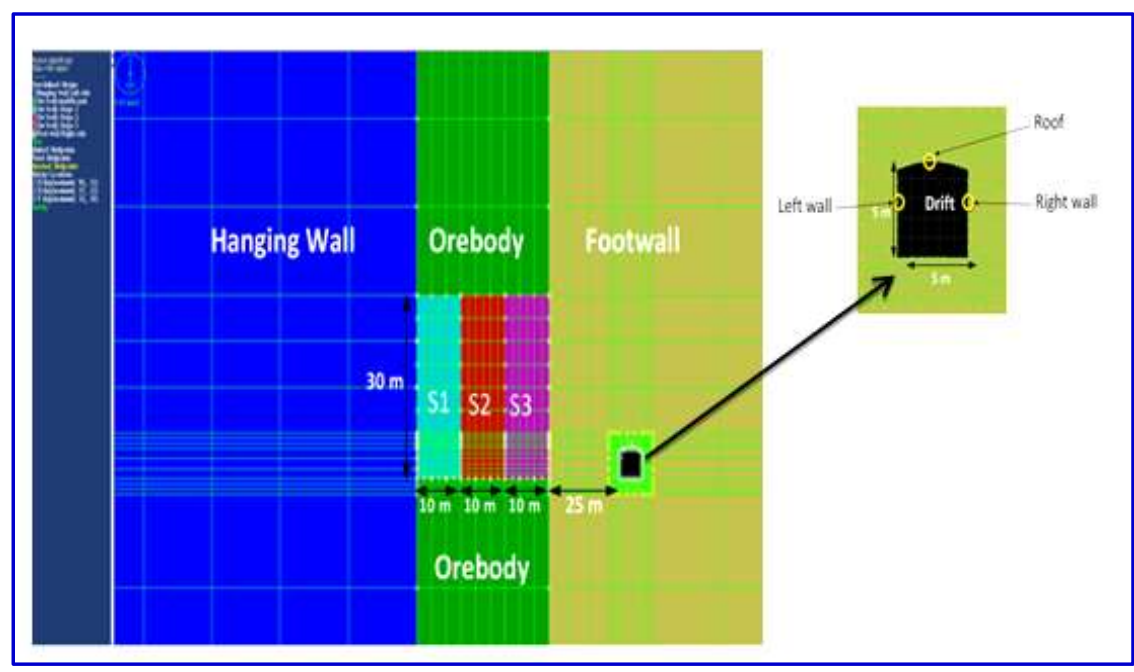

Fig. 3. Model set up and geometry 
JES, Assiut University, Faculty of Engineering, Vol. 43, No. 1, January 2015, pp. $71-81$

Table 1.

Geomechanical properties of the modelled case study

\begin{tabular}{|l|c|c|c|c|}
\hline \multirow{2}{*}{ Rockmass property } & \multicolumn{3}{|c|}{ Domain } & \multirow{2}{*}{ Backfill } \\
\cline { 2 - 4 } & Hanging wall & Orebody & Footwall & \\
\hline Density $\left(\mathrm{kg} / \mathrm{m}^{3}\right)$ & 2782 & 4531 & 2916 & 2000 \\
$\mathrm{UCS}(\mathrm{MPa})$ & 90 & 90 & 172 & 3 \\
$\mathrm{E}(\mathrm{GPa})$ & 25 & 20 & 40 & 0.1 \\
Poisson's ratio, $\vartheta$ & 0.25 & 0.26 & 0.18 & 0.3 \\
Cohesion, $\mathrm{C}(\mathrm{MPa})$ & 4.8 & 10.2 & 14.13 & 1 \\
Tensile strength, $\sigma_{\mathrm{t}},(\mathrm{MPa})$ & 0.11 & 0.31 & 1.52 & 0.01 \\
Friction angle, $\phi(\mathrm{deg})$ & 38 & 43 & 42.5 & 30 \\
Dilation angle, $\Psi(\mathrm{deg})$ & 9 & 11 & 10.6 & 0 \\
\hline
\end{tabular}

\section{Performance evaluation criteria}

Although there may be many other aspects to consider when evaluating the performance of mine haulage drift such as: deformation/displacement, mining-induced stress and extent of yield zones. In this investigation only a single condition; deformation/displacement; is considered and compared with different probabilistic methods. A wall convergence ratio (WCR) of $1.50 \%$ and roof sag ratio (RSR) of $0.50 \%$ are adopted as the minimum ratios required for "satisfactory performance" of the mine opening. Thus the unsatisfactory performance of the mine haulage drift is determined accordingly. Any deviation from the satisfactory performance criterion is thus classified to be a failure condition, i.e. when the WCR ratio $>1.5 \%$ and $\mathrm{RSR}>0.50 \%$. The deterministic analyses show the numerical modelling results in terms of displacement, mining-induced stress and extent of yield zones. However, in this study, the haulage drift stability performance will only be evaluated based on displacements/convergence criterion (e.g., WCR \& RSR).

\subsection{Displacements/convergence}

Displacement/convergence criteria are generally site specific; they depend not only on the rock mass stiffness characteristics but also on the purpose of the underground opening as well as the design and code requirements. In the following, three displacement-based criteria are presented [2].

\subsubsection{Wall convergence ratio (WCR)}

WCR is defined as the ratio of the total magnitude of the wall closure to the span of the initial drift as shown in Equation (3) (Zhang and Mitri, 2008):

$$
\mathrm{WCR}=\frac{\mathrm{W}_{0}-\mathrm{W}_{1}}{\mathrm{~W}_{0}} \times 100 \%=\frac{\Delta_{\max }}{\mathrm{W}_{0}} \times 100 \%
$$

Where:

$W_{0}$ is the original span of the drift and $W_{1}$ : is the span of the drift after deformation. The performance of mine haulage drift will be considered unstable/unsatisfactory if: $G(X)<0$ for all WCR $>1.5 \%$ and stable/satisfactory if: $\mathrm{G}(\mathrm{X}) \geq 0$ for all $\mathrm{WCR} \leq 1.5 \%$.

\subsubsection{Roof sag ratio ( $R S R)$}

RSR is defined as the ratio of the roof sag $(\Delta \mathrm{S})$ to the span of the drift as given in Equation (4) [2]: 
$\mathrm{RSR}=\frac{\Delta \mathrm{S}}{\mathrm{W}_{0}} \times 100 \%$

Where:

$W_{0}$ is the original span of the drift and $\Delta \mathrm{S}$ : is the roof sag. The performance of mine haulage drift will be considered unstable/unsatisfactory if: $\mathrm{G}(\mathrm{X})<0$ for all RSR $>0.50 \%$ and stable/satisfactory if: $\mathrm{G}(\mathrm{X}) \geq 0$ for all $\mathrm{RSR} \leq 0.50 \%$.

\subsection{Mining-induced stress}

This criterion adopts the stress concentration factor $(\mathrm{SCF})$, which is the ratio of the mining-induced major principal stress to the average in-situ stress or pre-mining stress $\left(\sigma_{0}\right)$.

$$
\mathrm{SCF}=\frac{\sigma_{1}}{\sigma_{0}}
$$

Where: $\sigma_{1}$, is the mining-induced major principal stress.

The value of SCF is usually used to determine the location and extent of high stress zone created by an excavation. If the SCF is more or less uniform around the mine opening, such opening is considered more stable [2].

\subsection{Extent of yield zones}

Yielding is the most common criterion used in numerical modeling when elasto-plasticity is employed. The condition of yielding is reached when the rock is loaded beyond its elastic limit. In this investigation, the Mohr Coulomb yield function is adopted and elasto-plastic behavior of the rock mass is used. Further, yielding will be considered a measure for the drift unsatisfactory performance if it extends beyond a certain depth into the drift roof and side walls (e.g., based on the type of rock support and its loading capacity).

\section{Numerical modeling mining step}

The numerical modelling steps are listed in Table 2 below.

\section{Table 2.}

Mining step for the modeled case study

\begin{tabular}{|c|l|}
\hline Step & \multicolumn{1}{c|}{ Operation } \\
\hline 1 & Excavate drift \\
\hline 2 & Excavate stope 1 \\
\hline 3 & Backfill stope 1 \\
\hline 4 & Excavate stope 2 \\
\hline 5 & Backfill stope 2 \\
\hline 6 & Excavate stope 3 \\
\hline 7 & Backfill stope 3 \\
\hline
\end{tabular}

\section{Deterministic results}

Deterministic analysis has been performed to investigate the effect of mining step on the mine haulage drift stability performance. The average values for physical and geomechanical properties of rock masses used in the deterministic analysis as model input parameters are listed in Table 1 above. In this paper, a deterministic analysis will be presented in terms of displacements (section 5.1: Figures 4-7), stress (section 5.2: Figure 8) and extent of yield zones (section 5.3: Figure 9) around haulage drift with respect to mining step. 


\subsection{Displacement/convergence}

Figure 4 shows that, after excavating drift both drift side walls move towards entire haulage drift. As mining starts to proceed, both sidewalls move towards mined stopes (e.g., big opening). The displacement versus mining steps is depicted as shown in Figure 5 below. Figure 5 depicts that, displacement increases and drift moves towards the orebody (e.g., stopes) as mining progresses. Alternatively, big openings/voids (e.g., mined stopes) attract the small opening (e.g., drift) to move towards them. The maximum displacement occurs in the right wall of haulage drift as mining progresses (e.g., $4 \mathrm{~cm}$ in the right wall after excavating stope 3 ). The mining step can be explained as listed in Table 2 below. The smallest deformation (e.g., deflection) occurs in the drift roof/back (e.g., $\cong 2 \mathrm{~mm}$ after excavating stope 3 ).
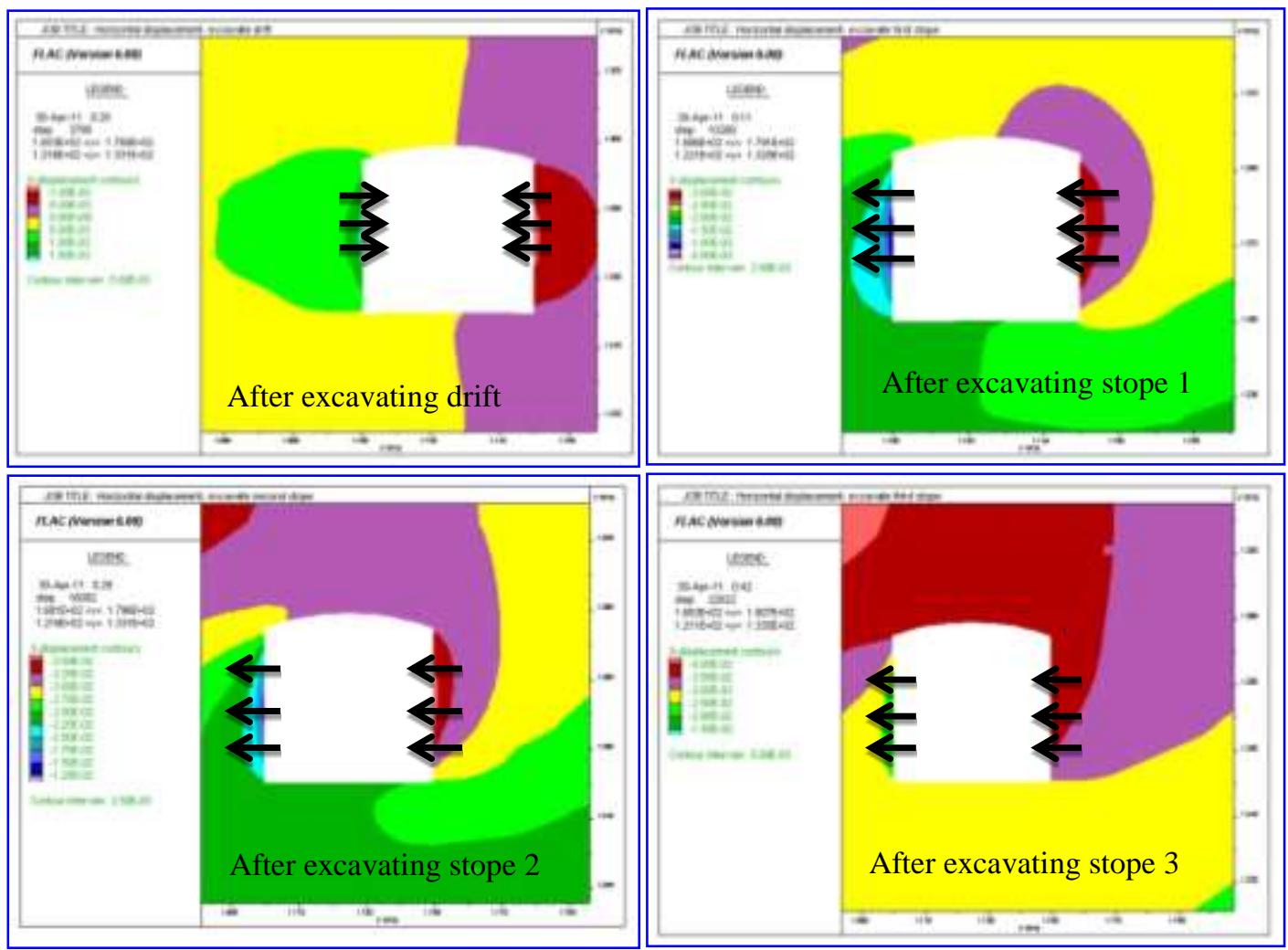

Fig. 4. Displacement contours around haulage drift as mining advances

The wall convergence ratio (WCR) for the drift side walls (e.g., left and right walls) and roof sag ratio (RSR) for the drift roof or back are shown in Figures 6 and 7 respectively. 


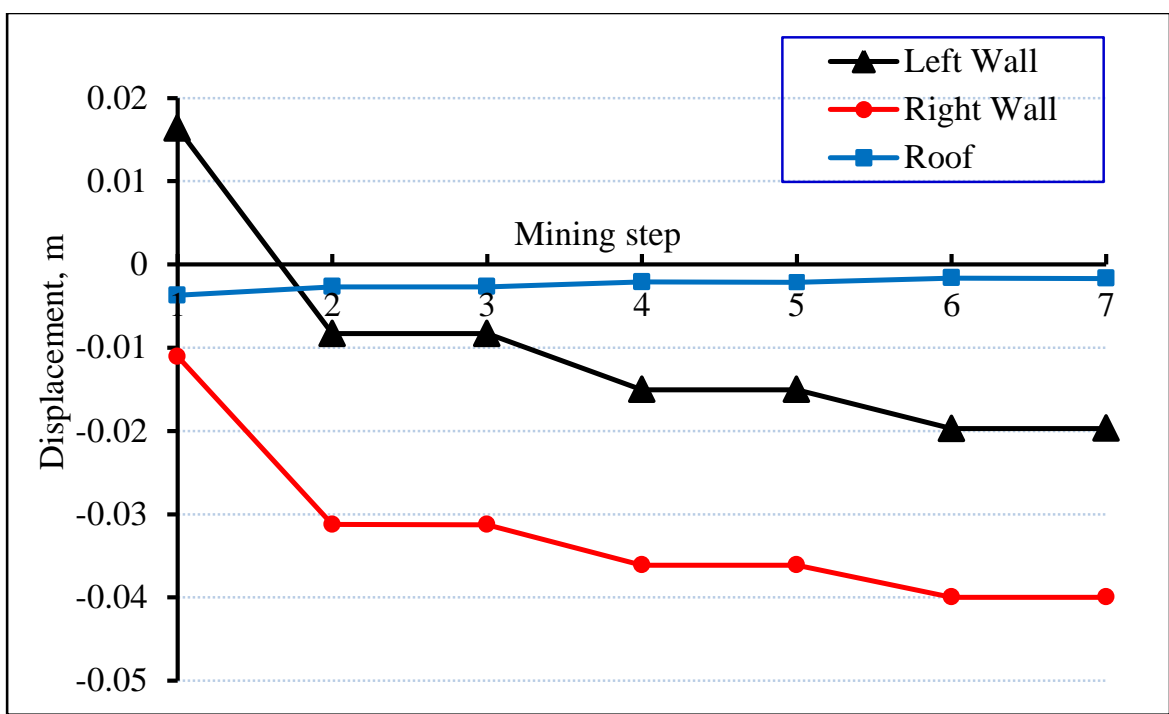

Fig. 5. Horizontal displacements versus mining step for the mine haulage drift

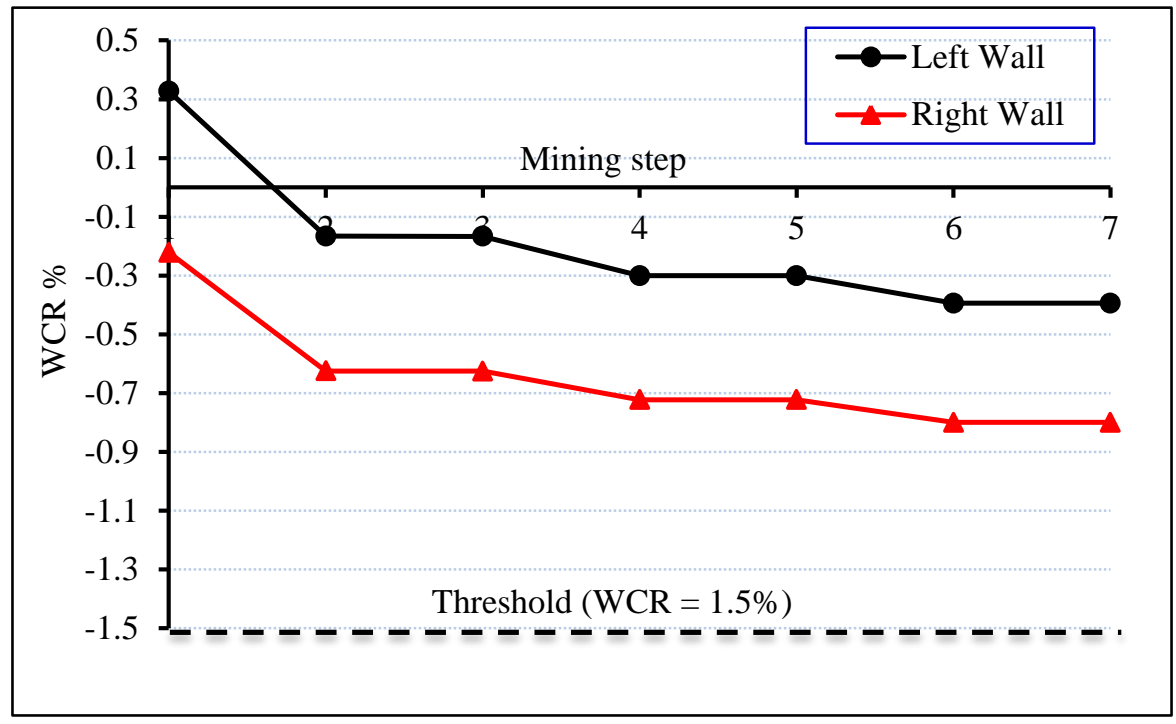

Fig. 6. Wall convergence ratio (WCR) versus mining step

Figure 6 shows that, the maximum WCR (e.g., $\cong 0.8 \%$ ) occurs in the drift right wall at last mining step (e.g., after excavating stope 3 or step 6). While for the left wall, the maximum WCR is $0.4 \%$ at the same mining step (e.g., step 6). Figure 7 shows that roof deflection increases as mining progresses. The highest RSR (e.g., $\cong 0.21 \%$ ) is found in the drift roof (back) after excavating stope 3 (e.g., step 6). 


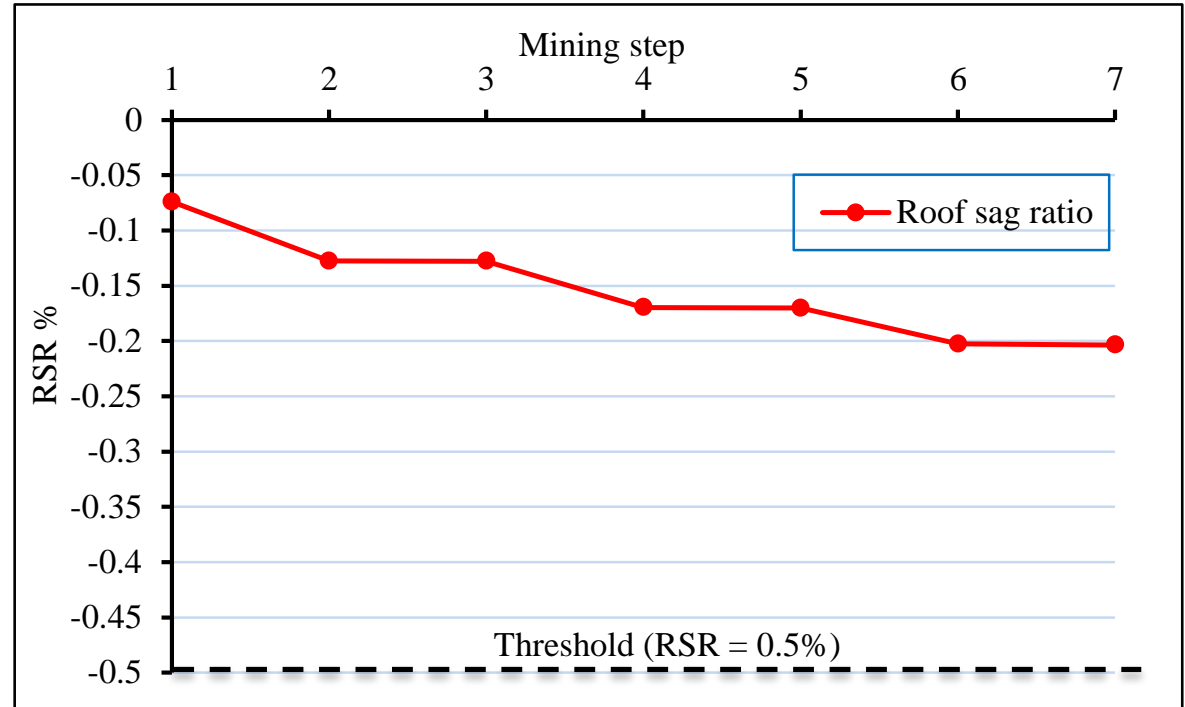

Fig. 7. Roof sag ratio (RSR) versus mining step

\subsection{Mining-induced stress}

Figure 8 shows the change in the stress distribution with respect to mining step. As mining advances there are more stress relaxation zones (e.g., decrease in the resulting compressive stress).

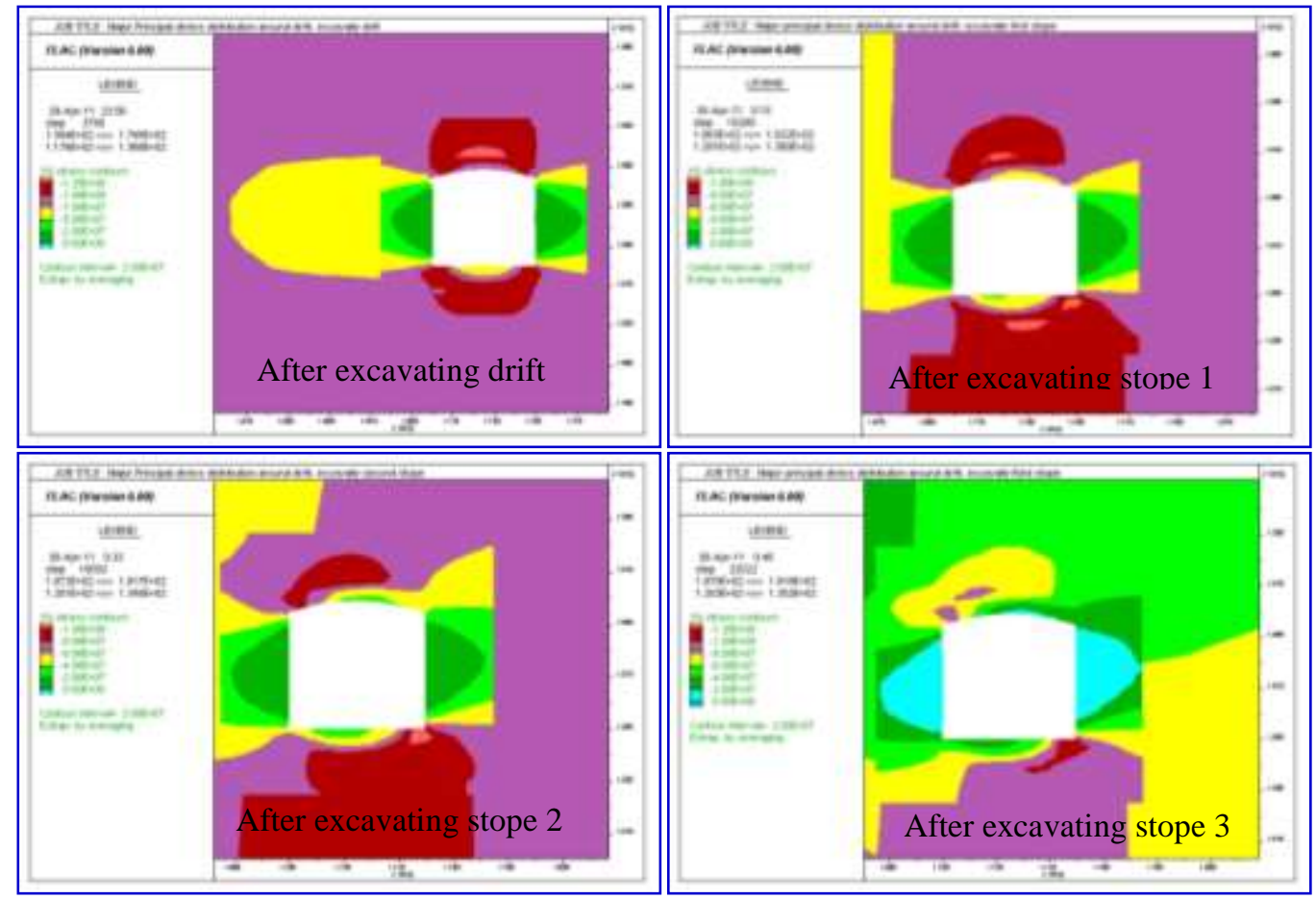

Fig. 8. Stress redistribution around mine haulage drift with respect to mining step 


\subsection{Extent of yield zones}

Figure 9 depicts the development of yield zones around the haulage drift as the mining proceeds. As shown in Figure 9, the length of yield zones increases and its contours extends especially in the left wall of haulage drift (e.g., sidewall faces orebody/mined stopes) as mining advances (e.g., after excavating stope 3 ).
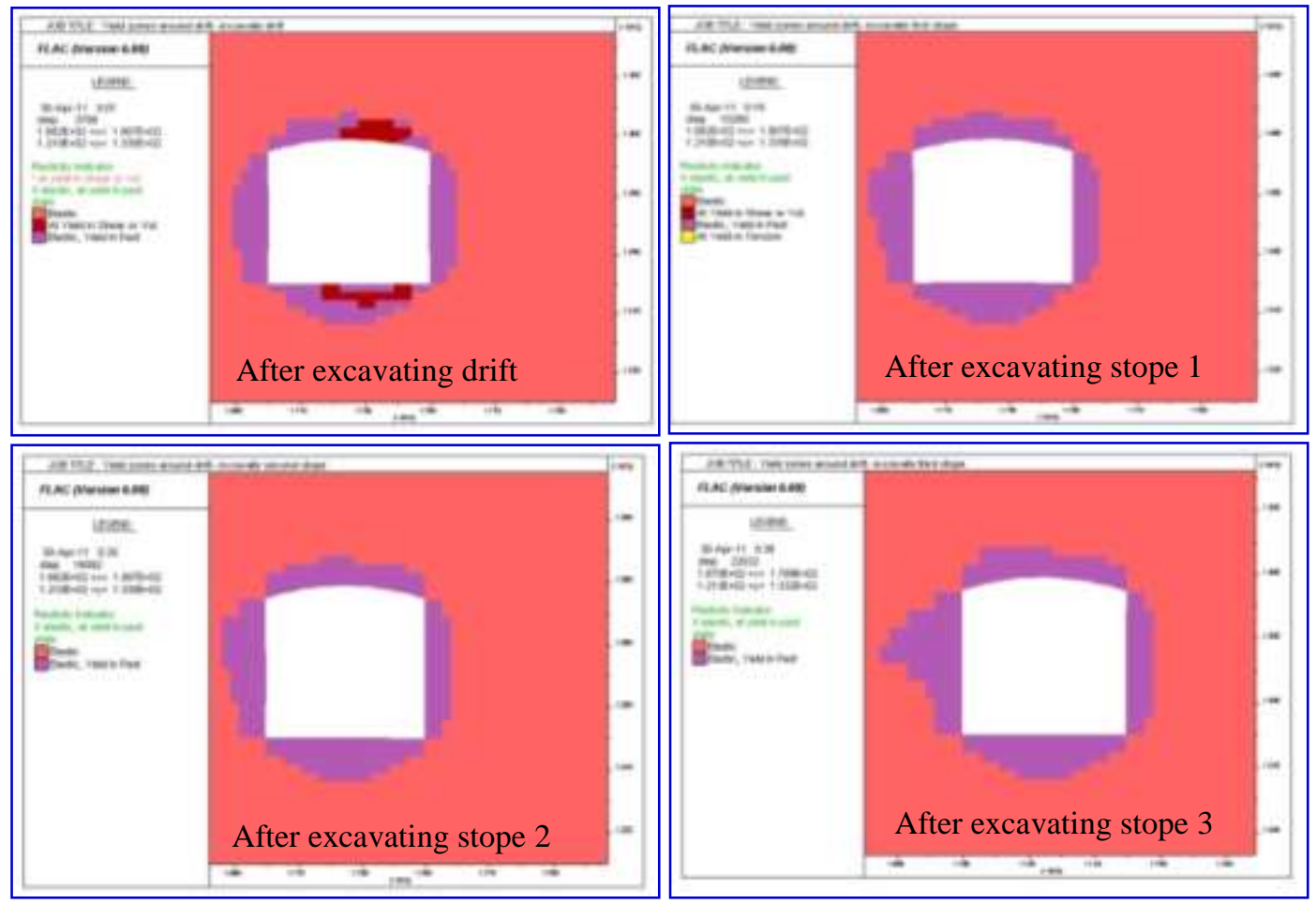

Fig. 9. Extents of yield zones around haulage drift with respect to mining step

\section{Conclusion}

This paper presents a stepwise methodology to assess the stability of mine haulage drifts with respect to mining activity. Two-dimensional elastoplastic, finite difference model (FLAC2D) is constructed to simulate the performance of haulage drift situated 1.5$\mathrm{km}$ below the ground surface. It is found that; drift excavation normally will cause convergence of the sidewalls. Thus the displacement will be in the direction of the void space. However, the excavation of the orebody in the form of mining stopes which are significantly larger than drift (i.e. stope is typically $10 \times 12 \times 30 \mathrm{~m}$ ) will have to effect. First, significant convergence of stope walls (inward displacement) will cause the drift to displace laterally towards the stope (lateral shift). Second, a loss of the horizontal stress results in the pillar between the stopes and the drift. Please see Zhang and Mitri (2008). For mining-induced stress, as mining activity progresses, there is less rockmass to support the mine structure and hence the condition of the haulage drift deteriorates. This can be attributed primarily to the stress redistribution caused by the removal of ore rock from the stope. Under these conditions, there is a strong possibility that the haulage drift could suffer from ground instability. For the yield zones, as the mining stope proceeds, the yield zones extend significantly. The maximum depth of yielding takes place in the drift left 
sidewall (after excavating stope 3 ). This would greatly exceed the normal practice for the regularly designed rock bolt length. The analysis also shows that the yield zone pattern is not symmetric and that it continues to grow around the drift back and floor, however, to a lesser extent, comparing with drift left wall.

The deterministic analyses (e.g., based on displacement/convergence criterion) reveal that no need for secondary support during the whole mining process (e.g., WCR $<1.5 \%$ \& RSR $<0.5 \%$ ). Alternatively, the haulage drift looks stable with all mining steps. However, due to inherent uncertainty in the model input parameters (e.g. rockmass properties), a stochastic analysis is recommended.

\section{Recommendation}

Three-dimensional modeling (3-D) is necessary to simulate the real geometry of the case study. In-situ stress measurements should be used to calibrate the numerical model. Model results must be validated based on underground measurements such as deformations (Multi-Point Borehole Extensometer or MPBX) and rock bolt loads.

\section{REFERENCES}

[1] Abdellah, W. (2013). Geotechnical Risk Assessment of Mine Haulage Drifts during the Life of a Mine Plan. Department of Mining and Materials Engineering, McGill University, Montreal, Quebec, Canada. Ph.D. Thesis.

[2] Zhang, Y. and H. S. Mitri (2008). "Elastoplastic stability analysis of mine haulage drifts in the vicinity of mined stopes." International Journal of Rock Mechanics and Mining Sciences (IJRMMS) 45: 574593.

[3] Kirsch, G. (1898). "Die theorie der elastizitat und die bedürfnisse der festigkcitslchre" Veit Ver DeutIng 42: 797-807.

[4] Bray B. and L. Lorig (1988). "Analysis of rock reinforcement using finite difference methods." Comp. Geotech 5(2): 123-149.

[5] Bray, B. (1977). "An analysis of rock behaviour in an experimental stoping block at the Mount Isa Mine. Geomech Abstr." Int. J Rock Mech. Min. Sci. Vol. (14): 59-66.

[6] Ladanyi, B. (1974). Use of the long-term strength concept in the determination of ground pressure on tunnel linings. Advances in rock mechanics, proceedings of the third congress, International Society of Rock Mechanics, Denver: National Academy of Sciences.

[7] ITASCA (2009). Fast Lagrangian Analysis of Continua in 3 Dimensions (FLAC3D), User's Manual Ver. 4.0 Minnesota 55401 USA, Itasca Consulting Group Inc., Minneapolis. 


\section{النمذجة العدية لاستقرار ممرات النقل فى المناجم تحت السطعية}

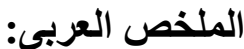

تعتبر ممر ات نقل الخام هى الثريان الرئيسى للمنجم. فهى تستخدم لنقل الخام من منطقة استخر اجه إلى أقرب ألقاب

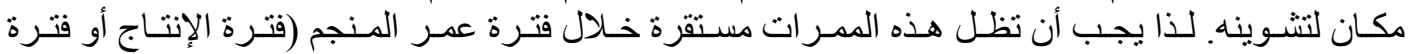

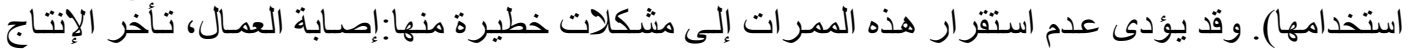

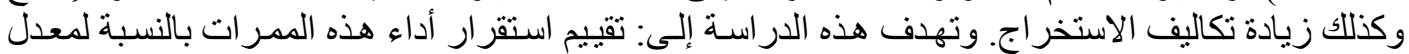

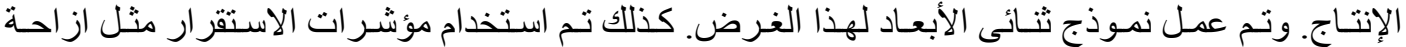
الممر ات من مكانها، الاجهادات حول الممر ات و امتداد مناطق انهيار الصخور مع التقدام في عملية الانتاج.

الكلمات الرئيسية: ممر ات نقل الخام - مؤشرات الاستقر ار ـ النمذجة العددية - خطة الاستخر اج. 